\title{
Academician Andrei Ershov and His Archive
}

\author{
Irina Kraineva and Natalia Cheremnykh \\ A.P. Ershov Institute of Informatics Systems of the SB RAS \\ Novosibirsk 630090, Lavrentiev ave., 6 \\ \{Cora, cher\}@iis.nsk.su
}

\begin{abstract}
Andrei Petrovich Ershov (1931-1988) was a mathematician and specialist in the field of programming theory and automation. A graduate of Moscow State University (1954), he worked in ITMCT AS (Academy of Sciences) USSR, in the AS USSR Computing Center. From 1961, he started working in the Siberian Branch of AS USSR (SB AS USSR): first in the Institute of Mathematics, from 1964 as the head of the Programming Division of the Computing Center, and then as head of the Experimental Informatics Laboratory. He was a doctor of Physical and Mathematical Sciences since 1967, a full member of the AS USSR since 1984, and professor. He was a member of the Association for Computing Machinery (ACM), a Distinguished Fellow of the British Computing Society, and vice-chairman of the IFIP Algol Working Group.
\end{abstract}

Keywords: history of informatics, academician Ershov, Siberian school of programming, optimizing translators, ALFA algorithmic language.

\section{Introduction}

The role of Andrei Ershov in the establishment and development of system programming in Russia cannot be overestimated. It is enough to say that it was under his guidance and immediate participation that the first optimizing translator from the Algol-like ALFA algorithmic language was developed; he is justly considered as the founder of mixed computations. Ershov was the first to start experimenting with teaching programming at schools; he authored the famous thesis "programming is the second literacy".

A.P. Ershov passed away very early. He was not even sixty, but his creative heritage still causes lively interest. One of the reasons for that is the unique archive containing over five hundred folders with documents reflecting the path of the academician and history of the development of informatics in the USSR. It sometimes seems that Andrei never in his life threw away a single piece of paper. Massive correspondence exists including over 5,000 letters, manuscripts of books and articles, reports, reviews, diaries, memos, even airplane and cinema tickets, invoices, even menus from ceremonial dinners and other material evidence of past events in different 
parts of the world. Ershov carefully collected and systematized all this both chronologically and by subject.

Upon Ershov's untimely death, his archive, together with his remarkable library, was passed by his heirs to the SB RAS Institute of Informatics Systems. The value of this unique archive was as obvious as the necessity to process and systematize its documents and put them into broad scientific circulation. The conventional tools for archive processing are considerably limited, which gave birth to the idea of using modern methods of electronic document processing and their presentation in the internet.

\section{Building the Archive}

In 2000, with the financial support from Microsoft Research, the work on the creation of the electronic version of the archive began. ${ }^{1}$ The work is performed by the employees of the Institute of Informatics Systems and the xTech company, and is supported by RFBR and RHF grants; UniPro and Atapy Software companies also contributed to the project. Currently, the work is close to completion. Historians of science are gaining access to the immense systematized bulk of documents that they can directly place into scientific circulation.

The documents in the archive were systematized by Ershov himself by subjectchronology principle and collected in folders devoted to certain subjects. They include materials from his trips to international and national programming forums, correspondence, documents related to research projects, drafts of articles and other scientific works, memos, scientific council meetings agendas, various official documents and much more. The structure of the electronic archive was prompted by this system; all documents were distributed by subjects that reflected consecutive steps in Ershov's life path; they showed different aspects of his activities. The archive is divided into twenty-eight subjects, which in turn contain groups and subgroups of documents united by common subject.

The earliest documents in the Ershov Archive date back to the times of his study in the 37th Boys School of Kemerovo. These are very curious biographic entries: several diplomas for excellent study and exemplary behavior, diplomas for winning sports tournaments, grades chart for the 1947/1948 academic year with only excellent marks, a draft of the written test in algebra at the exam for the school-leaving certificate. In the senior years at school Andrei took active part in extracurricular activities; he worked in the school Komsomol organization. In the autumn of 1947 the Komsomol regional committee awarded him with a tour to Moscow to the celebration of the capital's 800th anniversary and 30 years of the October Revolution. The Archive retains programs of shows in Lenkom (Lenin Komsomol Theatre), Mkhat (Moscow Art Academic Theatre), TsDT (Central Children's Theatre), Obraztsov Doll Theatre, tickets to Conservatory - evidence to the broad cultural program of the journey [1].

Several other folders contain notes and summaries of lectures from Ershov's student and postgraduate period. Among those is a modest notebook with eight lectures from the legendary course "Principles of Programming" delivered at the

${ }^{1}$ http://ershov.iis.nsk.su/ershov/russian 
Mathematics and Mechanics Department of the Moscow State University by Alexei Andreevich Lyapunov [2]. The first lecture took place on October 29, 1952, in the middle of the semester. Ershov recalls that these lectures were not regular university lectures, which a professor reads using summaries written well beforehand. Those were an improvisation. "We later realized, - Ershov wrote - that at the beginning of the course Alexei Andreevich knew about programming not much more than we did at the time. In a sense, he learned together with us. But these bits of knowledge, multiplied by his brilliant intellect and immense general and mathematical culture, allowed Alexei Andreevich to seize the fundamental nature of programming and create its methodology "[3].

The archive's documents reflect the difficulties of the preparation and defense of Andrei Ershov's PhD thesis. In 1958, his famous monograph, Programming program for fast electronic computing machine, was published. The book was printed in 4000 copies and appeared in bookstores on the 13th of August; a month later, on September 12, Ershov wrote in his diary: "PP is out of stock in bookshops! A pleasure for the author" [4]. Perhaps Andrei could have presented the book as his $\mathrm{PhD}$ thesis; however, he chose to write a more "mathematical" work. A.A. Markov, a well-known mathematician whom Andrei Petrovich deeply respected, agreed to be Ershov's opponent. It is clear from the diary notes that the work on the thesis went slowly and with difficulty, because Markov detained the manuscript for long periods. Nevertheless, Andrei considered all his remarks with great attention:

\footnotetext{
"Spent the day, excluding a short Sunday working-picnic for planting trees, making corrections to the dissertation according to Andrei Andreevich's remarks. He made twenty-eight remarks in the first fifty pages. Most of those can be easily taken into account. Despite that he let me down somewhat with timing, I am very grateful to him. After his reviewing the work will be almost flawless."
}

"Continued proof-reading the dissertation. Wrote a proof to the theorem on the connection between operator algorithms and graph schemes. In the evening talked to A.A. Markov. He strongly disliked programming expressions about "changing" programs, variable commands, etc. He proposed to exclude the parts dealing with the comparison of computational and conventional algorithms from the introduction, making it much less "programming". He is right in some points, especially when he talks of the fuzziness of programmer terminology, but he seems to misunderstand some things" [5].

In the end, A.A. Markov resigned from his responsibilities; Andrei Ershov defended his dissertation already in Novosibirsk, in 1962. His opponent was a famous algebraist, academician A.I. Maltsev.

From 1961, Andrei Ershov lived and worked in Akademgorodok, a suburb of Novosibirsk, where he moved on the invitation of one of the founders of SB AS USSR, academician S. L. Sobolev, director of the Institute of Mathematics. Andrei was to become head of the Algorithms Theory Laboratory of the institute. The archive contains documents reflecting the selection of staff, the research progress, and the everyday life of the newborn scientific center. 


\section{The Alpha Compiler}

The history of informatics in Siberia began, without doubt, with the beginning of the Alpha compiler project. Documents in the archive allow to trace its history. The first large project, which started under the supervision of Andrei Ershov first in the Institute of Mathematics and continued later in the Computing Center of the SB AS USSR, where Andrei transferred with his Programming Division in 1964, immediately grabbed the attention of world scientific community. In 1966, Ershov received a letter from K. Levitin, the editor of Znanie-Sila ("Knowledge is Power") magazine, where Levitin wrote: "Last Wednesday - on the 30th of March - M. A. Lavrentiev gave a talk in the Central House of Literature about Akademgorodok. While answering a question he mentioned your name - in the following context:

"We have a scientist, Andrei Petrovich Ershov, - he said - whom the Americans have been trying to entice for a long time. They invite him over to work - for a year, or two, or for as long as he likes, together with the family, on the most attractive terms with a 3000 \$-per-month salary and additional payments for consulting. In our country, he is a mere $\mathrm{PhD}$ " [6].

There are several thick "log books" in the archive, each reflecting a stage in the creation of the Alpha compiler. They are called accordingly, The Birth of $\alpha$-Compiler, The childhood of $\alpha$-Compiler, Puberty of $\alpha$-Compiler [7]. Notes were added almost every day. At first, the logs reflected the project progress, and later, when debugging began, log notes began to play an even more important role. The developers briefly summed up the results of running a program, marked mistakes, passed information to colleagues who took shift after them in the computer room. Other final, preliminary and intermediate reports on scientific research projects (there are over 30 of them in the archive) reflect research, production and science managerial side of the activities of research groups headed by Andrei Ershov.

A. P. Ershov was one of the most "out-going" Soviet scientists - he made over fifty foreign trips in the course of thirty years of his active scientific career, although the number of invitations he received was much greater. However, Ershov's first trip to the USA in 1965 could have become his last one. He then gave a talk devoted to the Alpha-compiler at the IFIP Congress. Americans showed great interest in the state of affairs in the Soviet computer technology, and arranged Andrei an additional trip to San Francisco and Los Angeles. Based on Ershov's talk given at the Los Angeles ACM division, an article by R. Henkel appeared in the Electronic News, called "Soviet Expert on Soviet Machines: Not Enough and Not Too Good". The article caused violent feedback in the motherland: the President of the USSR Academy of Sciences, M.V. Keldysh, sent an angry letter to G.I. Marchuk, the director of the SB AS USSR Computing Center at the time, in which he accused Ershov of distortion of information about computer technology in the USSR and even of unauthorized disclosure. Unfortunately, we were unable to find that letter, neither in SB RAS nor in RAS archives. Ershov's reply, however, survived. While essentially answering the accusations, he simultaneously expressed many remarkable ideas concerning cooperation with the USA in the area of computer technology [9]. This document is a unique testimony of Andrei's ability to analyze clearly the situation, the strong character of the still very young man and his skill to stand upon his rightness. The scientific reports on Ershov's foreign trips, whose drafts remain in the archive, were 
repeatedly published both in magazines and as separate brochures, always being a source of new knowledge and fresh ideas [10].

\section{Comments and Correspondence}

Ershov attended a great number of international conferences, congresses and seminars, and the archive contains materials about their organization and holding: invitations, characteristics from party committees, which were an indispensable for anyone wishing to travel outside the country at those times. In this respect the story of the organization of the International Colloquium on Mixed Computations, which took place in Denmark in 1987, is a telling example. A Danish scientist, D. Bjorner, organized the colloquium. He managed to find considerable funds for the support of soviet scientists who achieved notable results in the area of mixed computations that caused broad interest among specialists worldwide.

Documents in the archive allow us to trace the formation of the soviet delegation and the difficulties caused by party officials that it had to cope with. There remain letters of Andrei Ershov to academician E. P. Velikhov, who at the time was head of the AS Informatics Division and whom Andrei addressed as the ultimate authority. Several members of the delegation were denied permission to leave the country; among them was S. S. Lavrov, head of the Institute of Theoretical Astronomy, who received a party penalty shortly before. Ershov wrote to Velikhov:

"Evgeni, I strongly believe that the situation with the trip to Denmark is the case when one should separate events in the institute and Lavrov's directorial duties from the advisability of his participation in the seminar on mixed computation. We shouldn't hinder this worthy and important event. I am asking you to support us by calling comrade Fateev ${ }^{2}$ " [11].

As a result, Lavrov was able to attend the colloquium, yet some of the candidates for the trip did not pass the "party control".

The archive contains remarkable examples of biographic genre: essays about Ershov's close colleagues - talented, but deceased untimely: Gennady Kozhukhin, with whom they began work on the input language for Alpha-compiler, Gennady Zvenigorodski, a wonderful programmer and teacher, who put his energy into teaching programming to schoolchildren. Andrei wrote many heartfelt warm words about his colleagues and teachers: A.A. Lyapunov, G.I. Marchuk, E.V. Dijkstra, and others. These works portrait the images of first programmers as well as show the directions of scientific research of the period. When Yu.I. Manin read the essay about Dijkstra, he remarked:

"The text is full of natural and kind feeling. In the strange atmosphere of hostility and
aggression, which is getting so dense in the professional communities of Moscow that
I belong to, living becomes cramped and sultry. I recall remorsefully my own silent
participation in the sittings of "Uspekhi MN" editorial staff, where "problems" such
as lack of permission to publish anniversary articles in honor of A or B, or the
question of whether we could call C outstanding when D had already been called
famous, were discussed - and other rotten nonsense of the kind." [12].

${ }^{2}$ Presiding Commissioner for Foreign Trips of Leningrad regional committee of the Communist Party. 
Andrei was truly interested in the history of science, and not only computer science: He recorded interviews with a prominent Russian economist, academician Aganbegyan, the Polish computer scientist V.M. Turski, a, the president of the SB AS USSR, academician M.A. Lavrentiev. Parts of the interview with Lavrentiev were used in Ershov's and M.R. Shura-Bura's joint work, The Establishment of Programming in the USSR. Curiously, the manuscript mimics Lavrentiev's manner of speech so authentically that it reminds a transcription of a tape recording:

"We needed twenty-thousand lamps. But they would give only five thousand to the whole Academy. We tried this and that, but then got an idea. So we go straight to the radiotechnics people and say, how's your military acceptance, doesn't it bother you? You don't ask, they answer, we're wasting all our time on that, how do you check them? And we say, let's make a deal. You make us a revolving fund of 20 thousand lamp, we install them, record modes and give all data back to you. They were only happy to make a deal, so we got our lamps. Parshin ${ }^{3}$ was mad: "A-holes! Those lousy academicians are cheating us!" [13]

Ershov's voluminous correspondence is especially interesting. The archive contains about five thousand letters Andrei sent or received. People addressed him with all sorts of questions. Different people wrote to Andrei, and he answered many of them personally. There are, for example, numerous letters from the period of introduction of informatics into the school course. This innovation had many proponents and just as many opponents. Among those who wrote were baffled schoolchildren, to whom the new subject seemed too difficult, and teacher worried by the lack of required training. There were, however, many letters that Ershov answered with pleasure. Those include a very serious letter from a high school student asking which college to choose in order to become a qualified computer science specialist [14]. Andrei maintained long-lasting scientific and friendly correspondence with many outstanding scientists such as D. Knuth, J. McCarthy, E. Dijkstra, Yu.I. Manin, and V.M. Glushkov as well as business correspondence with academicians M.V. Keldysh, A.A. Dorodnitsyn, A.I. Berg, and others.

\section{Non-computing Areas}

Since most of Andrei's life was connected with Akademgorodok, many documents reflect that special atmosphere which formed here thanks to the concentration of intelligent and multi-talented personalities. Life-science discussions on the subject "Life of wonderful ideas" in the SB AS House of Scientists attracted numerous participants and listeners who eagerly witnessed the progress of scientific research. There remain materials of Ershov's public speeches, when he took part in discussions with the audience. Notes from the audience in the archive speak of the sincere interest of the public to the new branch of science - the creation of artificial intelligence: "When will a working model of cognition be constructed?" "Do they use the achievements of physiology of higher nervous activities and psychology in the

\footnotetext{
${ }^{3}$ P.I. Parshin. The Minister of the USSR engineering and instrument-making industries (19461953, 1954-1956).
} 
creation of artificial intelligence?" "Won't the creation of artificial intelligence pose any danger to mankind?" [15]

The archive contains several short essays Andrei wrote under the impression of casual observations. They testify to Ershov's undoubted literary talent, convey impressions and moods and truthfully represent the spirit of the moment. Once, walking on the shore of the Ob Lake, Andrei saw academician A. M. Budker, director of the Institute of Nuclear Physics, skating. Andrei wrote about this bright memory after over twenty years:

"It was in the year 1961 or 1962 . November. The Ob Lake froze, but the snow hadn't fallen yet. A natural skating rink formed. A group of people on the ice, dressed in winter clothes already. And there was Andrei Mikhailovich in a whitish scarf, skating alone. I watched him for five minutes or so. He definitely felt in the focus of events. One could see he was happy about this early winter, and was feeling the swift ease of skating once again, youthfully. I recall this scene again and again, and it conjures up an image of perky, brisk beginning of a new life." [16]

The image of the archive wouldn't be full without mentioning the documents which characterize the personality of Andrei. In July of 1987, Ershov was elected to the Organizing Committee of the V. I. Lenin Novosibirsk Sovietski District Children's Fund. On October 14, 1987, he took part in the work of the Establishing Conference of the Fund as an Executive Board member. Shortly before that, on the $12^{\text {th }}$ of October, Andrei transferred 1000 rubles to the Fund from his personal savings. Andrei was deeply touched by the problems of orphaned children, and he repeatedly addressed the chairman of the Novosibirsk Sovietski District V. V. Generalov, asking him to support the initiative of Z. V. Borodayevskaya, a citizen of Akademgorodok, for the establishment of a family-style orphanage and provision of a cottage in Akademgorodok [17]. The decision was made in March of 1989, already after Ershov's death, when Zoya Vladimirovna and her six foster children moved to a house on Zolotodolinskaya Street. This family of ten still thankfully remembers the invaluable help from Andrei.

\section{Conclusion}

Ershov was a jovial man, always the soul of the party since the university years. He played guitar, sang, wrote poetry; he loved theatre, books and music. A good song never left him indifferent. Looking through the notes Andrei made in the course of his preparation for the exam on the theory of differential variable as a postgraduate, we found a handwritten text of a song from the film called Vernye druzia (True Friends), put down on paper hastily right after it was broadcast on the radio. It was April of 1955... [18]. During his trip to England in 1958 to the International symposium on mental processes automation he attended a concert of Royal Philharmonic - one of the four most important orchestras of Great Britain, and saved the program carefully [19]. He was lucky to listen, among other things, to the Haydn's London Symphonies, performed by an orchestra conducted by Sir Thomas Beecham - the piece specialists consider to be the most masterful achievement of this conductor. As a souvenir he brought sheetmusic and lyrics of "Happy birthday" written down by Patricia, the daughter of V. Bricks, employee of Elliot Brothers (London) Ltd [20]. 
One can find in the archive manuscripts of practically any of Ershov's articles and monographs. Two voluminous folders contain articles and materials reflecting different points of view upon the subject of informatics [21]. Perhaps Andrei collected these materials for another article ors book. A very interesting detail are the numerous notes with marks such as "Ideas and wishes in store"or "Idea!" [22]. Not only historians of science but also actively working researchers may find useful information in these manuscripts, and maybe even borrow some new ideas or find a creative stimulus in Andrei Ershov's the old but still relevant works.

Acknowledgment. The authors acknowledge those who have helped with the sources and development of this article. In particular, they are appreciative of the support provided by RFH, project № 05-03-12304.

\section{References}

1. A.P. Ershov's Archive. Memorabilia from the tourist trip to Moscow in (November 1947), http: //ershov.iis.nsk.su/archive/ eaimage. asp?did=13292\&fileid=130921

2. Notes of A.A. Lyapunov's lectures Principles of programming, http://ershov.iis.nsk. su/archive/eaimage. asp? lang=1\&did=3104 4 \&fileid=164717

3. Ershov, A.: In memory of Alexey Andreevich Lyapunov (talk at the memorial session of Siberian Mathemaical Society, pp. 243-245 (October 15, 1973), A.P. Ershov's Archive Folder 532

4. Department Head's Journal, A.P. Ershov's Archive - Folder 35, p. 104

5. ibidem, p. 111

6. Letter from Levitin, K., to Ershov, A. (April 2, 1966), http: / / ershov.iis.nsk. su/archive/eaindex. asp?lang=1\&did=20004

7. Journal ALPHA compiler: the birth. Events log (22.05.63-29.10.63), http: / / ershov.iis.nsk.su/archive/eaindex. asp? lang=1\&did=2757

8. Henkel, R.: Soviet Expert on Soviet Units: Not Enough and Not Very Good - Electronic News (July 07, 1965),

http: / /ershov.iis.nsk.su/archive/eaindex. asp?lang=1\&did=26958

9. Letter from Ershov, A., Keldysh, M. (July 20, 1965), http: //ershov.iis.nsk.su/archive/eaindex. asp?lang=1\&did=20854

10. Ershov, A.P.: Computer Science in the USA. Based on the trip to the 3rd IFIP Congress, USA (May 25-29, 1965), Moscow, Computing Center of USSR AS, p. 339 (1966), http: //ershov.iis.nsk.su/archive/eaindex. asp?lang=1\&did=12425

11. Letter from Ershov, A. to Velikhov, E. (July 25, 1987), http://ershov.iis.nsk.su/archive/ eaimage. asp?did=3046\&fileid=80959

12. Letter from Manin, Y. to Ershov, A. (Januray 15, 1981), http: //ershov.iis.nsk.su/archive/eaimage.asp?fileid=77610

13. Ershov, A.P.: Interview with academician M.A. Lavrentiev (October 26, 1967), http://ershov.iis.nsk.su/archive/ eaimage. asp?did=17909\&fileid=137068 
14. Letter from Ershov, A. to Rechkalov, I. (March 10, 1986), http://ershov.iis.nsk.su/archive/ eaimage. asp? lang $=1 \& d i d=6347 \&$ fileid $=90637$

15. Notes received during the discussion on artificial intelligence (March 20, 1978), http: / / ershov. iis.nsk.su/archive/eaindex. asp?lang=1\&did=5147

16. Ershov, A.P.: Diary entry (December 9, 1984), http://ershov.iis.nsk.su/archive/eaimage.asp?fileid=161701

17. Letter from Ershov, A. to Generalov, A. (June 27, 1988), http://ershov.iis.nsk.su/archive/eaimage.asp?lang=1\&did=7462 \&fileid=90536

18. Notes of lectures on the differential variable theory (April 1955), http: / / ershov.iis.nsk.su/archive/eaindex . asp? lang=1\&did=12576

19. Programme of the Royal Philarmonic Orchestra Concert, http: //ershov. iis.nsk.su/archive/eaindex. asp?lang=1\&did=6368

20. Happy birthday: sheet music and lyrics (December 1958), http: //ershov. iis.nsk.su/archive/eaindex.asp?lang=1\&did=6363

21. A.P. Ershov's Archive. Folders 267, 268

22. Ershov, A.: In-store Ideas and Wishes, http: //ershov.iis.nsk.su/archive/eaimage.asp?fileid=137023 